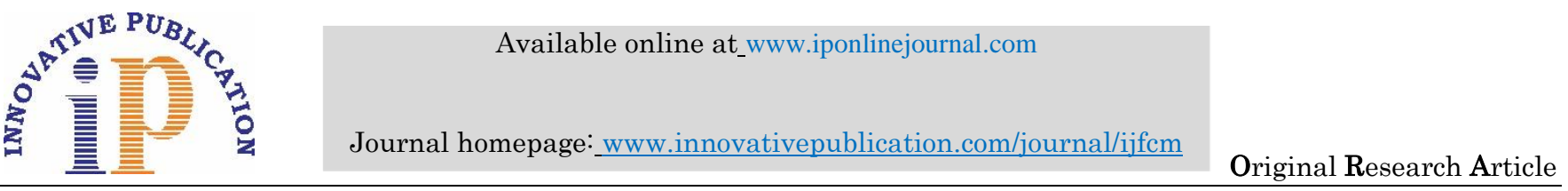

\title{
A cross sectional study of hypertension among the elderly residing in urban field practice area of S. N. Medical College, Bagalkot, Karnataka
}

\author{
Anamika Patel ${ }^{1}$, Gowri Shankar ${ }^{2 *}$ \\ ${ }^{1}{ }^{\text {rd }}$ Year Post Graduate, ${ }^{2}$ Professor, ${ }^{\mathbf{1 , 2}}$ Dept. of Community Medicine, S Nijalingappa Medical College, HSK (Hanagal Shree Kumareshwar) \\ Hospital and Research Centre, Bagalkot, Karnataka, India
}

\begin{abstract}
Introduction: Longevity has increased significantly in the past few decades due to demographic transition in India. So there is likely to be a huge burden of chronic non-communicable diseases in the near future. Hypertension is one of the most important treatable causes of morbidity in the elderly. It accounts for a large proportion of cardiovascular diseases in the elderly. Hence this study was done to know the socio-demographic profile and the prevalence of Hypertension among the elderly more than 60 years of age residing in urban field practice area of S.N. Medical College, Bagalkot.

Materials and Methods: A cross sectional community based study was done in urban field practice area of S. N. Medical College, Bagalkot, Karnataka.

According to a previous study done in Karnataka, the prevalence of hypertension among the elderly was $30.7 \%$ and sample size was calculated to 627 .

Blood pressure measurement was done using the auscultatory method with a standardized calibrated mercury column sphygmomanometer.Data analysis was done using SPSS software version 20.

Result: Out of 627 elderly studied, males were $48.32 \%$ and females were $51.67 \%$. Majority $(64.27 \%)$ of the elderly were in the age group of 60-69 years followed by $28.36 \%$ between $70-79$ years and $7.6 \%$ more than 80 years and above. Overall prevalence of hypertension among elderly is $51.99 \%$. [Males $48.15 \%$ and females $51.84 \%$ ]. Prevalence of overweight and obesity in hypertensives $17.2 \%$ and $66.9 \%$ in males and $12.4 \%$ and $53.3 \%$ in females respectively. Consumption of tobacco and alcohol was found to be more among males who are hypertensives. $(\mathrm{p}<0.000)$
\end{abstract}

Conclusion: There is increased need of outreach services for adequate health care of the elderly in developing countries like India.

Keywords: Hypertension, Elderly, Urban area.

\section{Introduction}

"Ageing is a universal process" in the words of Seneca, "Old age is an incurable disease"

In the words of Sir James Ross, "You cannot heal old age; you protect it, promote it and extend it". Though advancements in modern technologies and medicine have occurred, a greater number of humans are surviving into later life with the potential to reach the age of 120 years. This phenomenon known as the "rectangularization" or "box shaping" of the survival curve of man, suggest that the average life span of man is increasing. ${ }^{1}$ The word Geriatrics was coined by Nascher in 1914. The meaning of "gerus and iatra" being "old age and treatment". Senescence is the process of ageing. Changes that are an outcome of a lifelong interaction between two opposing processes:

1. One representing evolution/growth, and

2. The other involution/atrophy ${ }^{2}$

Longevity has increased significantly in the past few decades due to demographic transition in the country. India is going to be having the highest number of Elderly with multimorbidity of non communicable disease in the world by year 2025. Developing countries are thus likely to face a huge burden of chronic non-communicable diseases in the near future. Of these diseases, hypertension is one of the most important treatable causes of mortality and morbidity in the elderly. ${ }^{3}$ It accounts for a large proportion of cardiovascular diseases in the elderly. ${ }^{4-6}$

Hence, this study was done to know the sociodemographic profile and the prevalence of Hypertension among the elderly more than 60 years of age residing in urban field practice area of S.N. Medical College, Bagalkot, Karnataka.

\section{Materials and Methodology}

A cross sectional community based study was done during January-December 2018 in urban field practice area of S.N. Medical College, Bagalkot after Ethical clearance. According to a study done during 2010 in rural areas of Davanagere, the prevalence of hypertension among the elderly was $30.7 \%$. $^{7}$ The sample size was calculated to be 627.

According to Census 2011, elderly is $8.1 \%$ of total population in India and the population of study area was 18803. Estimated elderly population in the study area was 1523. Thereby, sampling interval calculated to 2.42. Every $2^{\text {nd }}$ elderly individual included in the study.

\footnotetext{
*Corresponding Author: Gowri Shankar, Dept. of Community Medicine, S Nijalingappa Medical College, HSK (Hanagal Shree Kumareshwar) Hospital and Research Centre, Bagalkot, Karnataka, India

Email: patelanamika26@gmail.com

http://doi.org/10.18231/J.IJFCM.2019.027
} 
Table: Definition of hypertension (Based on JNC-VII criteria) ${ }^{8}$

\begin{tabular}{|c|c|c|}
\hline Blood Pressure & $\begin{array}{c}\text { Systolic } \\
(\mathbf{m m} \text { of } \mathbf{~ H g})\end{array}$ & $\begin{array}{c}\text { Diastolic } \\
(\mathbf{m m} \text { of } \mathbf{H g})\end{array}$ \\
\hline Normal & $<120$ & $<80$ \\
\hline Prehypertension & $120-139$ & $80-89$ \\
\hline $\begin{array}{c}\text { Stage-1 } \\
\text { hypertensives }\end{array}$ & $140-159$ & $90-99$ \\
\hline $\begin{array}{c}\text { Stage-2 } \\
\text { hypertensives }\end{array}$ & $>160$ & $>100$ \\
\hline
\end{tabular}

\section{Inclusion criteria}

Permanent residents of urban field practice area who were residing for more then 1 year and willing to participate in the study. Written informed consent in the local language was taken from all study subjects, before enrolment in the study. Data was collected by interview technique by house to house survey using predesigned and semi-structured questionnaire.Information regarding socio-demographic factors and type of diet consumed was assessed from the questionnaire.

\section{Hypertension measurement}

Using the auscultatory method with a standardized calibrated mercury column type sphygmomanometer and an appropriate sized cuff encircling at least $80 \%$ of the arm in the seated posture, with feet on the floor and arm supported at heart level.

Following a standardized protocol, three separate measurements were recorded after proper rest and the average of the three measurements was calculated. Systolic
$\mathrm{BP}$ is the point at which the first of 2 or more sounds is heard (phase I) and diastolic BP is the point before the disappearance of sounds (phase 5). Data was compiled and tabulated by M S Excel spread sheet. Statistical software Open Epi was utilized for analysis.

\section{Results}

Majority (64.27\%) of the elderly were in the age group of $60-69$ years followed by $28.36 \%$ between $70-79$ years and $7.6 \%$ more than 80 years and above. Out of 627 elderly $324(51.92 \%)$ were females and $303(48.32 \%)$ were males. Hindus were maximum $(78.14 \%)$ in the area, followed by $12.12 \%$ Muslims and $9.72 \%$ of other religions. Maximum $(49.12 \%)$ lived in joint family and $31.10 \%$ in nuclear family and $19.77 \%$ lived alone. Among them $19.75 \%$ were single living females and $19.80 \%$ were single living males. The education status of study population shows that maximum $(55.82 \%)$ were illiterates. Majority of the elderly $(64.27 \%)$ belonged to class V followed by $28.54 \%$ to class IV, $3.66 \%$ belonged to class III, $2.39 \%$ to class II and $1.11 \%$ belonged to class I under Modified BG Prasad Classification.

Overall prevalence of hypertension among elderly was 51.99\%. [Males - 48.15\% and females -51.84\%] Among 627 elderly, $29.98 \%$ were known hypertensives on treatment. On examination, persistence of higher side of blood pressure $(>140 / 90 \mathrm{mmHg})$ was found in $120(63.82 \%)$ [Males - 52(43.33\%) and females - 68(56.66\%)]

Incidence of hypertension among elderly is $42.33 \%$ hypertensives. (Table1 and Table2)

Table 1: Distribution of the different classes of elderly hypertensives as per JNC-VII

\begin{tabular}{|c|c|c|c|}
\hline Blood Pressure (Systolic/ Diastolic mm of Hg) & JNC-VII & N & Percentage \\
\hline$<120 / 80$ & Normal & 121 & 19.29 \\
\hline $120-139 / 80-89$ & Pre-hypertension & 180 & 28.70 \\
\hline $140-159 / 90-99$ & Stage-1 hypertensives & 173 & 27.59 \\
\hline$>160 / 100$ & Stage-2 hypertensives & 153 & 24.40 \\
\hline
\end{tabular}

Table 2: Association between age, gender and JNC scoring of hypertension as per JNC-VII $(\mathrm{n}=326$, male $=157$, females $=169)$

\begin{tabular}{|c|c|c|c|c|c|c|c|c|c|c|}
\hline & Normal & $\%$ & Pre-HTN & $\%$ & Stage-I & $\%$ & Stage-II & $\%$ & $\mathbf{X}^{2}$ & P-value \\
\hline \multicolumn{11}{|c|}{ Sex } \\
\hline Male & 61 & 50.4 & 85 & 47.2 & 95 & 54.9 & 62 & 40.5 & \multirow[t]{2}{*}{7.036} & \multirow[t]{2}{*}{0.71} \\
\hline Female & 60 & 49.6 & 95 & 52.8 & 78 & 45.1 & 91 & 59.4 & & \\
\hline Total & 121 & 100 & 180 & 100 & 173 & 100 & 153 & 100 & & \\
\hline \multicolumn{11}{|c|}{ Age (in years) } \\
\hline $60-69$ & 72 & 61.7 & 113 & 62.8 & 114 & 65.9 & 62 & 103 & \multirow[t]{3}{*}{9.453} & \multirow[t]{3}{*}{0.66} \\
\hline $70-79$ & 36 & 29.7 & 54 & 30 & 48 & 27.7 & 39 & 25.5 & & \\
\hline$\geq 80$ & 13 & 10.7 & 13 & 7.2 & 11 & 6.4 & 11 & 7.2 & & \\
\hline
\end{tabular}

This study shows that majority of the elderly who had mixed diet had hypertension (51.5\%).In the hypertensives, $17.2 \%$ males and $12.4 \%$ females were Overweight and $66.9 \%$ males and $53.3 \%$ females were Obese. The association of gender with dietary pattern $(\mathrm{p}<0.004)$ and Body Mass Index $(\mathrm{p}<0.000)$ was found to be statistically significant $($ Table 3$)$. 
Table 3: Association of elderly hypertensives with gender, dietary habits and Asian Classification of Body Mass Index (Male $=303$, Female $=324$ ).

\begin{tabular}{|c|c|c|c|c|c|c|c|c|}
\hline 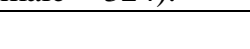 & \multicolumn{2}{|c|}{ Male } & \multicolumn{2}{|c|}{ Female } & \multicolumn{2}{|c|}{ Total } & $\mathrm{X}^{2}$ & P-value \\
\hline Dietary Habits & No & $(\%)$ & No & $(\%)$ & No & $(\%)$ & & \\
\hline Vegetarian & 65 & 41.4 & 57 & 33.7 & 122 & 37.4 & 11.209 & 0.004 \\
\hline Non- Vegetarian & 8 & 5.1 & 28 & 16.6 & 36 & 11.0 & & \\
\hline Mixed & 84 & 53.5 & 84 & 49.7 & 168 & 51.5 & & \\
\hline BMI(Asian) & No & $(\%)$ & $\mathrm{No}$ & $(\%)$ & No & $(\%)$ & & \\
\hline$<18.5$ & 5 & 3.2 & 33 & 19.5 & 38 & 11.7 & 22.680 & 0.000 \\
\hline $18.5-22.9$ & 20 & 12.7 & 25 & 14.8 & 45 & 13.8 & & \\
\hline $23.0-24.9$ & 27 & 17.2 & 21 & 12.4 & 48 & 14.7 & & \\
\hline$\geq 25.0$ & 105 & 66.9 & 90 & 53.3 & 195 & 59.8 & & \\
\hline
\end{tabular}

Consumption of tobacco (chewers as well as smokers) and alcoholics were more among hypertensives and was statistically found to be significant $(\mathrm{p}<0.000)[$ Table 4]

Table 4: Association of elderly hypertensives with gender and habits

\begin{tabular}{|c|c|c|c|c|c|c|c|c|}
\hline Habits & Male & $\%$ & Female & $\%$ & Total & $\%$ & $\mathbf{X}^{2}$ & P-value \\
\hline \multicolumn{9}{|c|}{ Smoking } \\
\hline Current Smoker & 20 & 12.7 & 8 & 4.7 & 28 & 8.6 & \multirow[t]{3}{*}{28.698} & \multirow[t]{3}{*}{0.000} \\
\hline Ex-addict & 41 & 26.1 & 14 & 8.3 & 55 & 16.9 & & \\
\hline Never & 96 & 61.1 & 147 & 87.0 & 243 & 74.5 & & \\
\hline \multicolumn{9}{|c|}{ Alcohol Intake } \\
\hline Current drinker & 12 & 7.6 & 4 & 2.4 & 16 & & \multirow[t]{4}{*}{28.294} & \multirow[t]{4}{*}{0.000} \\
\hline Ex-addict & 31 & 19.7 & 10 & 5.9 & 41 & & & \\
\hline Occasional & 91 & 58.0 & 13 & 7.7 & 104 & & & \\
\hline Never & 23 & 14.6 & 142 & 84.0 & 165 & & & \\
\hline \multicolumn{9}{|c|}{ Tobacco consumption } \\
\hline Current chewer & 44 & 28.0 & 22 & 13.0 & 66 & 20.2 & \multirow[t]{3}{*}{24.057} & \multirow[t]{3}{*}{$\mathbf{0 . 0 0 0}$} \\
\hline Ex-addict & 30 & 19.1 & 15 & 8.9 & 45 & 13.8 & & \\
\hline Never & 83 & 52.8 & 132 & 78.1 & 215 & 65.9 & & \\
\hline
\end{tabular}

\section{Discussion}

In our study, majority $(64.27 \%)$ of the elderly were in the age group of 60-69 years followed by $28.36 \%$ between 70 79 years and $7.6 \%$ more than 80 years and above. Out of 627 elderly 324(51.92\%) were females and 303(48.32\%) were males.

Majority of the elderly were in the age group of 60-69 years. More number of females lived longer in age groups 60-69 and 70-79 compared to males. ${ }^{9}$ Kammar et al. observed that $40 \%$ of the elderly were illiterate. ${ }^{10}$

In the present study, $64.27 \%$ elderly belonged to class $\mathrm{V}$ followed by $28.54 \%$ to class IV, $3.66 \%$ belonged to class III, $2.39 \%$ to class II and $1.11 \%$ belonged to class I under Modified BG Prasad Classification. Manda et al. observed that $27.2 \%$ of the elderly subjects were in class $\mathrm{V}$ (poor) whereas our study showed $64.27 \%$ were in class V. ${ }^{11}$

Various studies estimated a prevalence rate of hypertension among urban population ranging from $1.24 \%$ in 1949 to $36.4 \%$ in $2003 .^{12}$ The overall prevalence of hypertension among elderly in our study was observed to be $51.99 \%$ and a large proportion $28.70 \%$ of elderly in the prehypertensive group). Similarly a previous study done by Das Shyamal Kumar et al. showed a large proportion of sample population in the pre-hypertensive group. ${ }^{8}$ These participants are of great interest since chance of progression to hypertension is high. According to the study conducted by Hazarika et al. $3.36 \%$ of the hypertensives undergoing treatment were under control. ${ }^{13}$ Similarily, among $29.98 \%$ known case of hypertension, 14(7.44\%) are under control in our study.

In our study the association of gender with that of dietary pattern $(p<0.004)$ and Body Mass Index $(p<0.000)$ was found to be statistically significant (Table 3 ).

Similarly the association of hypertension with BMI and dietary pattern have been reported in the past studies showed direct relation with increased blood pressure. ${ }^{14,15}$ The recent increase in overweight and obesity in the United States both in adults and children may explain, in part, the associated increase in hypertension prevalence over the past decade. ${ }^{16}$ Based on a review of NHANES III data, the southern region of the United States, which includes the "stroke belt," has dietary patterns that may contribute to the high prevalence of hypertension and cardiovascular disease in that region. ${ }^{17}$ Clinical trial evidence also suggested that blood pressure is decreased by diets rich in fruits and vegetables, lower in salt, and high in nonfat dairy products. $^{18}$

The consumption of tobacco (chewers as well as smokers) and also alcoholics in our study were more among 
hypertensive males than females and was statistically found to be significant $(\mathrm{p}<0.000)$. Prevalence of smoked and smokeless tobacco consumption in India is $20 \%$. It is significantly higher in males than in females $(28 \%$ in males and $12 \%$ in females) and in rural population as compared to urban population. ${ }^{19}$ The contribution of alcohol to the prevalence of hypertension attributed to consuming more than two drinks per day has been estimated to be $5 \%$ to $7 \% .^{20}$

\section{Public health implications}

Hypertension is a major risk factor for heart disease and stroke. Recent data from Eastern Asia demonstrate a stronger association of hypertension with risk of stroke in this part of the world compared to the West. ${ }^{21}$

These findings provide strong support for attempts to detect and treat hypertension in India. These under-score the importance of alerting the public health community to the impending burden of hypertension in the elderly in the near future, with its accompanying clinical and economic consequences. In tandem with a population based strategy to reduce blood pressure, it is important to implement individual-based programe that permit identification and treatment of hypertension in general, and in the elderly in particular.

We recommend formulation of a National Hypertension Programme that investigates environmental factors associated with hypertension, encourages physicians as well as other health care professionals to routinely record blood pressure measurement; build an infrastructure for research and education in high blood pressure. Such a programme could adapt international guidelines keeping in mind local priorities, cultural, economic and social realities. It should evaluate benefits, feasibility and cost-effectiveness of drug treatment, which would be able to target local practitioners more effectively. ${ }^{22}$

\section{Conclusion}

In our community-based study of elderly subjects in Bagalkot Urban field practice area, we observed that $51.99 \%$ of individuals over the age of 60 years had elevated blood pressure. We noted a striking lack of awareness of the condition among the subjects and a suboptimal rate of control among those treated. These findings emphasize the public health importance of hypertension in the elderly in the State, and the likely increase in magnitude of this problem in the country in the near future.

\section{Acknowledgement}

I thank Dr. Santhoshkumar R Naik, Co-PG in supporting for the completion of the article. I also thank Mrs. Sarojini S. Hunashikatti and Mr. Nikhil Savadatti for their support in collection of data and also thankful to study population for giving the information about their health status.

\section{Source of Funding}

None.

\section{Conflict of interest}

None.

\section{Ethical Approval}

The study was approved by the Institutional Ethics Committee

\section{References}

1. Park K. Parks Textbook of Preventive and Social Medicine, 25th edition. Jabalpur, India: Bhanot Publishers. 2019:650-2.

2. Lal S, Adarsh, Pankaj. Text book of Community Medicine, 5th edition. New Delhi: CBS Publishers. 2018:649-50.

3. National High Blood Pressure Education Program Working Group. National High Blood Pressure Education Program Working Group Report on Hypertension in the Elderly, Hypertension, 1994;23:275-85.

4. Burt VL. Prevalence of hypertension in the US adult population. Results from the Third National Health and Nutrition Examination Survey, 1988-1991. Hypertens 1995;5:305-13.

5. Trenkwalder P, Ruland D, Stender M, Gebhard J, Trenkwalder $\mathrm{C}$, Lydtin $\mathrm{H}$ et al, Prevalence, awareness, treatment and control of hypertension in a population over the age of 65 years: results from the Starnberg Study on Epidemiology of Parkinsonism and Hypertension in the Elderly (STEPHY). $J$ Hypertens 1994;12(6):709-16.

6. O'Donnel CJ, Kannel WB. Cardiovascular risks of hypertension: Lessons from observational studies. J Hypertens 1998;16(suppl):S3-S7.

7. Yuvaraj BY, Nagendra Gowda MR, Umakantha AG. Prevalence, awareness, treatment, and control of hypertension in rural areas of Davanagere. Indian J Community Med 2010;35(1):138.

8. Das SK, Sanyal K, Basu A. Study of urban community survey in India: growing trend of high prevalence of hypertension in a developing country. Int J Med Sci 2005;2(2):70.

9. Sudarshan BP, Chethan TK. Morbidity pattern among the elderly population in the rural area of Pondicherry: a cross sectional study. Int J Community Med Public Health 2017;3(2):414-8.

10. Kamma MR, Kamath R, Ashalatha KV. Functional Abilities of the Aged. Indian J Gerontol 2011;25(1):41-50.

11. Manda PK, Chakrabarty D, Manna N, Mallik S, Chatterjee C. Disability among geriatric females: an uncared agenda in rural India. Sudanese J Public Health 2009;4(4):376-82.

12. Nissien A, Bothig S, Grenroth H, Lopez AD. Hypertension in developing countries. World Health Stat Q 1988;41:141-54.

13. Hazarika NC, Biswas D, Mahanta J. Hypertension in the elderly population of Assam. J Association Physicians India 2003;51:567-73.

14. Stamler J. Epidemiological Findings on Body Mass and Blood Pressure in Adults. Ann Epidemiol 1991;1:347-62.

15. $\mathrm{Hu} \mathrm{FB}$ et al. Body mass index and cardiovascular risk factors in a rural Chinese population. Am J Epidemiol 2000;151:8897.

16. Bruce NG, Wannamethee G, Shaper AG. Lifestyle factors associated with geographic blood pressure variations among men and women in the UK. J Human Hypertens 1993;7(3):229-38.

17. Hajjar I, Kotchen T. Regional variations of blood pressure in the United States are associated with regional variations in dietary intakes: the NHANES-III data. $J$ Nutr 2003;133(1):211-4.

18. Appel LJ, Moore TJ, Obarzanek E, Vollmer WM, Svetkey LP, Sacks FM et al, A clinical trial of the effects of dietary patterns on blood pressure. New Engl J Med 1997;17;336(16):1117-24. 
19. Rani M, Bonu S, Jha P, Nguyen SN, Jamjoum L. Tobacco use in India: prevalence and predictors of smoking and chewing in a national cross sectional household survey. Tobacco Control 2003;12(4):e4-.

20. Colli A, Cocciolo M, Mumoli N, Cattalini N, Fraquelli M, Conte D et al. Hepatic artery resistance in alcoholic liver disease. Hepatol 1998;28(5):1182-6.

21. Stroke E and Coronary Heart Disease Collaborative Research Group. Blood pressure, cholesterol and stroke in Eastern Asia. Lancet 1998:352:1801-7.
22. Kalavathy MC, Thankappan KR, Sarma PS, Vasan RS. Prevalence, awareness, treatment and control of hypertension in an elderly community-based sample in Kerala, India. National Med J India 2000;13(1):9-15.

How to cite this article: Patel A, Shankar G. A cross sectional study of hypertension among the elderly residing in urban field practice area of s. n. medical college, Bagalkot, Karnataka. Indian J Forensic Community Med 2019;6(3):116-120. 